\title{
Alluaudite polyanionic frameworks for rechargeable sodium-ion batteries
}

\author{
Debasmita Dwibedi ${ }^{1}$, Prabeer Barpanda ${ }^{1}$ \\ ${ }^{1}$ Materials Research Centre, Indian Institute of Science, Bangalore, India \\ E-mail: debasmitadwibedi09@gmail.com
}

To satiate the global energy demand, efficient energy generation and storage is crucial. Here, electrochemical energy storage in general and rechargeable batteries in particular is the most viable devices for energy storage and (mobile) delivery. While lithium-ion batteries has ushered the wireless revolution over the last three decades, ever growing concern over natural lithium reserves has stimulated major interest in sodium-ion batteries as economic alternatives, particularly for large-scale storage applications. But, be it Li-ion or Na-ion technologies, both need to be improved in order to match the energy density, operational safety and sustainability as required by myriads of energy hungry applications. Addressing such challenges - "Energy Storage (R)Evolution" vastly relies on innovation of new cathode materials along with the optimization of existing ones.

In this prospect, inorganic materials with three dimensional polyanionic framework are viable battery materials, due to their ability to store and transport alkali ions. In addition, the presence of channels in these polyanionic materials provides means for the insertion of alkali ions while maintaining the structural stability. Chemists have garnered great success in discovery of suites of polyanionic framework insertion materials such as borates, phosphates, fluorophosphates, pyrophosphates, silicates, sulfates, flurosulphate etc. Among them, sulfate compounds deliver the highest operation potentials due to the presence of stronger electron withdrawing sulphate groups. One of the early sulfate materials to be studied for sodium insertion capabilities was NASICON class of $\mathrm{Fe}_{2}\left(\mathrm{SO}_{4}\right)_{3}$, which can intake multiple $\mathrm{Na}^{+}$ions to form $\mathrm{Na}_{2} \mathrm{Fe}_{2}\left(\mathrm{SO}_{4}\right)_{3}$. In a recent breakthrough, a completely different polymorph of $\mathrm{Na}_{2} \mathrm{Fe}_{2}\left(\mathrm{SO}_{4}\right)_{3}$ was discovered by Barpanda et al. Having an alluaudite mineral structure, it has benchmarked the highest ever $\mathrm{Fe}^{3+} / \mathrm{Fe}^{2+}$ redox potential (ca. $3.8 \mathrm{~V} \mathrm{vs}^{2} \mathrm{Na}^{+} / \mathrm{Na}^{0}$ ) with excellent cyclability and rate kinetics. It has led to unprecedented focus on 'alluaudite' framework insertion materials.

The origin of such high redox voltage is tantalizing, which can be correlated to its crystal structure. $\mathrm{Na}_{2} \mathrm{Fe}_{2}\left(\mathrm{SO}_{4}\right)_{3} \mathrm{Stabilizes}$ into a monoclinic framework (s.g. C2/c), which is built from unique edge sharing of transition metal octahedra (TMO6) that are in turn interconnected by $\mathrm{SO}_{4}$ tetrahedral units. This renders large open channels along $b$ axis for sodium (de)insertion. Inspired by this beautifully channelized crystal structure of $\mathrm{Na}_{2} \mathrm{Fe}_{2}\left(\mathrm{SO}_{4}\right)_{3}$, in the present study, we have extended the alluaudite family by discovering isostructural $\mathrm{Na}_{2} \mathrm{Mn}_{2}\left(\mathrm{SO}_{4}\right)_{3}$ and $\mathrm{Na}_{2} \mathrm{CO}_{2}\left(\mathrm{SO}_{4}\right)_{3}$ analogues. Synergizing X-ray diffraction, Rietveld refinement, bond valence sum analysis and electrochemical measurements, we have identified the Na-ion migration pathways that enable these alluaudite materials to act as superior cathodes for next generation rechargeable sodium batteries. We will describe the synthesis and structural aspects of various $\mathrm{SO}_{4}^{-}$based alluaudites and compare them with $\mathrm{PO}_{4}{ }^{-}$based and $\mathrm{MoO}_{4}{ }^{-}$based alluaudite cathodes.

[1] Barpanda, P. et al. (2014). Nature Commun. 5, 4358.

[2] Dwibedi, D. et al. (2015). J. Mater. Chem. A. 3 18564-18571.

[3] Dwibedi, D. et al. (2016). ACS Appl. Mater. Interfaces. 8 6982-6991.

[4] Dwibedi, D. et al. (2016). Dalton Trans. 46. 55-63.

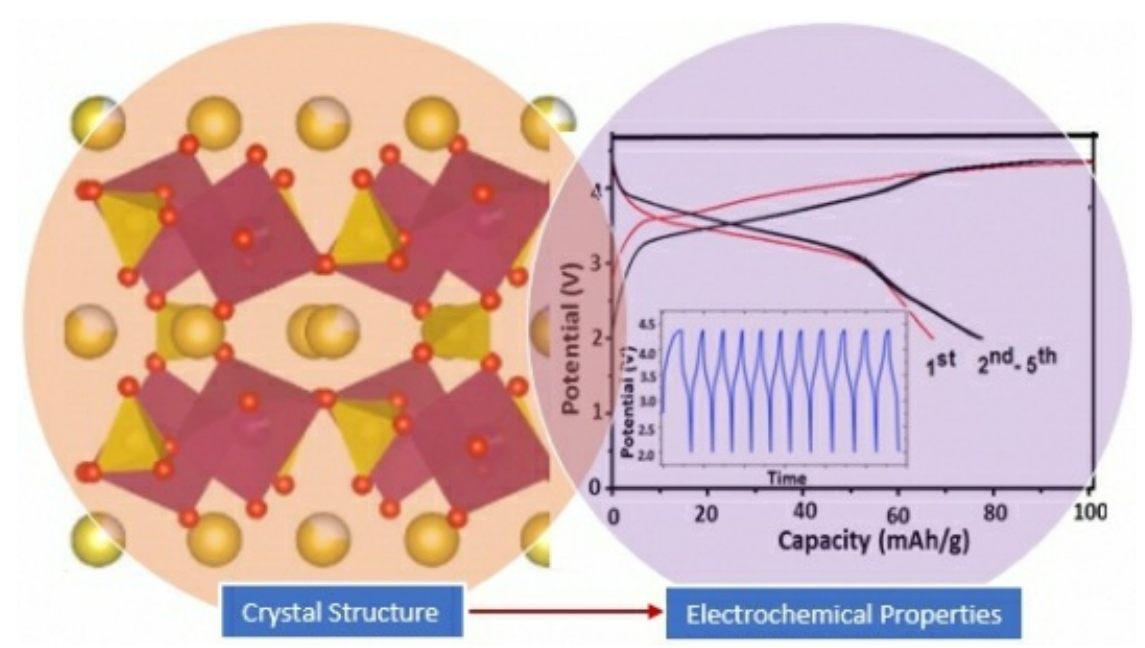

Keywords: Polyanionic framework, Alluaudites, Rietveld refinement 